\title{
Control of the diffusive boundary layer on benthic fluxes: a model study
}

\author{
B. A. Kelly-Gerreyn*, D. J. Hydes, J. J. Waniek \\ National Oceanography Centre, Southampton, University of Southampton, Waterfront Campus, European Way, \\ Southampton SO14 3ZH, UK
}

\begin{abstract}
A simple, steady state, reaction-diffusion diagenesis model is used to quantify the possible error associated with benthic flux measurements which neglect the presence of the diffusive boundary layer (DBL). Model application is restricted to non-bioturbated, fine-grained sediments in which oxygen consumption is dominated ( $65 \%$ of the consumption budget) by organic carbon degradation, oxygen penetration depths are low $(<0.5 \mathrm{~cm})$ and solute exchange across the sedimentwater interface (SWI) is diffusive. The effect of different thicknesses of the DBL is tested on sediments with different organic carbon reactivities $\left(k=1,5,10,20,40 \mathrm{yr}^{-1}\right)$. When imposing the range of DBL thicknesses observed in nature $(0.01$ to $0.1 \mathrm{~cm})$ on the model, the model simulates lower oxygen fluxes (by up to $22 \%$ for $k=40 \mathrm{yr}^{-1}$ ) across the SWI compared to fluxes simulated in the absence of a DBL. Greater reactivity increases the impact of the DBL by lowering the oxygen penetration depth. Changes in the DBL directly influence oxygen fluxes and aerobic mineralisation by changing the diffusion path length to a relatively thin oxic sediment layer. The changes in anaerobic processes are small $(<8 \%$ for denitrification and $<3 \%$ for sulphate reduction) and, together with the associated solute fluxes (nitrate, sulphate, ammonium) across the SWI, occur in response to changes in porewater oxygen concentrations induced by the DBL, rather than by direct interactions with the DBL. Changes included a $380 \%$ increase in nitrate influxes and a $90 \%$ reduction in nitrate effluxes. Rates of nitrification decreased by up to $18 \%$. Thicker DBLs also decreased the organic carbon degradation rate by a maximum of $22 \%$, implicating the DBL as a factor in organic carbon preservation for highly reactive sediments. Measurements of near-bed currents in a macro-tidal estuary (Southampton Water, UK) suggest that the observed range in DBL thicknesses can exist for up to $31 \%$ of the time (sampling period: 3 to $4 \mathrm{mo}$ ). The presence of these DBL thicknesses in such a dynamic environment, makes it is reasonable to assume that the establishment of the DBL may be widespread. Consequently, it is only reasonable to neglect the DBL over sediments in which aerobic mineralisation is dominant, when organic reactivity is low.
\end{abstract}

KEY WORDS: Diffusive boundary layer - Benthic fluxes - Organic carbon reactivity - Early diagenesis model

Resale or republication not permitted without written consent of the publisher

\section{INTRODUCTION}

The diffusive boundary layer (DBL), also known as the diffusive sublayer, is the microlayer directly above the sediment-water interface (SWI) through which molecular diffusion is the dominant mode of transport for dissolved substances. The thickness of the DBL is generally in the range 0.02 to $0.12 \mathrm{~cm}$ (e.g. Santschi et al. 1983, 1991). Experimental studies have indicated that changes in the thickness of the DBL can affect oxygen fluxes across the SWI (Jørgensen \& Des Marais 1990, Huettel et al. 2003, Lorke et al. 2003). Modelling studies have shown that thicker DBLs lower the flux of oxygen to the sediment (Hall et al. 1989). Archer et al. (1989) expanded on this by predicting that the lower the oxygen penetration depth (OPD), the greater the reduction in the oxygen flux in the presence of a DBL. This is 
because lower OPDs mean that a greater proportion of the sediment depth versus concentration profile of oxygen is contained within the DBL. The predictions of Archer et al. (1989) suggest that oxygen dynamics should be most affected by the DBL in shallow coastal sediments where thin oxic layers (i.e. low OPD, <0.5 cm) are often observed (Revsbech et al. 1980, Lohse et al. 1996, Nedwell \& Trimmer 1996, Rysgaard et al. 2001). However, such predictions contrast with the theoretical study of Jørgensen \& Boudreau (2001). These authors concluded that the DBL has a negligible effect on oxygen fluxes over shallow sediments in which oxygen consumption is driven primarily by the reoxidation of the reduced by-products of organic degradation (e.g. sulphide). Many coastal studies (e.g. Jørgensen 1982, Mackin \& Swider 1989, Canfield et al. 1993) show that benthic oxygen consumption is mostly fuelled by the reoxidation of reduced substances and that anaerobic degradation often dominates the decomposition pathways of organic matter, offering support to the Jørgensen \& Boudreau (2001) study. Consequently, Jørgensen \& Boudreau (2001) concluded that organic carbon preservation was unaffected by the DBL because oxygen fluxes were fuelled by reoxidation processes rather than by carbon mineralisation. Other field studies show that oxygen consumption via sedimentary organic carbon respiration is more important than via reoxidation processes in some shelf environments (southern North Sea: Upton et al. 1993, Slomp et al. 1997; NW European shelf: Lohse et al. 1998; Canadian shelf: Silverberg et al. 2000; Kattegat and Skagerrak: Rysgaard et al. 2001). The effect of the DBL on both benthic fluxes and diagenetic processes under these sedimentary conditions has not been investigated.

The aim here is to use a simple model of early diagenesis (Kelly-Gerreyn et al. 1999) to examine the effect of different thicknesses of the DBL on benthic fluxes for sediments in which (1) oxygen consumption is dominated by organic carbon degradation, (2) OPDs are low $(<0.5 \mathrm{~cm})$ and (3) dissolved fluxes across the SWI are predominantly diffusive (i.e. non-bioturbated sediments). The latter criterion means that the sediments considered here are fine-grained (less permeable, $<10^{-12} \mathrm{~m}^{-2}$ ) and therefore not influenced by advective flow (see Forster et al. 1996). The effect of the DBL on oxygen fluxes and for the first time on nitrate, ammonium and sulphate fluxes is investigated along with the responses of other model quantities, e.g. porewater concentration profiles, organic carbon mineralisation rates and other associated processes. This will quantify the potential error associated with benthic flux measurements which neglect the presence of the DBL.

\section{MODEL DESCRIPTION}

The model is a 1-D reaction-diffusion model of early diagenesis in which 5 variables $\left(\mathrm{O}_{2}, \mathrm{NO}_{3}{ }^{-}, \mathrm{NH}_{4}{ }^{+}, \mathrm{SO}_{4}{ }^{2-}\right.$ and $\mathrm{S}^{2-}$ ) are modelled from steady state distributions of total organic carbon (TOC). The model is a 1-G type model (Berner 1980) which assumes a simple first order dependence of organic degradation on the concentration of TOC and has been shown to represent observations well (Rabouille \& Gaillard 1991, Kelly-Gerreyn et al. 1999). Organic carbon mineralisation is mediated via oxygen, nitrate and sulphate, with each pathway producing ammonium (and dinitrogen in the case of nitrate reduction and free sulphide in the case of sulphate reduction). Rates of organic carbon mineralisation are colimited by the organic carbon concentration and the electron acceptor (i.e. oxygen for respiration via oxygen, nitrate for denitrification, sulphate for sulphate reduction) concentration. Inhibition functions (see Eq. 6) define the mechanism (e.g. oxygen inhibition of denitrification) by which the depth stratified sequence of biogeochemical zones observed in nature are represented in the model. Other model processes include sulphide reoxidation and nitrification, both of which consume and are limited by oxygen. Iron and manganese cycling are not included as the model is applied to sediments in which oxygen consumption is dominated by aerobic carbon oxidation and where the latter dominates carbon mineralisation. Consequently, it is assumed that the sulphide formed diffuses upwards and is readily reoxidised in the oxic layer. The model sediment is described with 150 layers, each $0.1 \mathrm{~cm}$ thick, yielding a total sediment depth of $15 \mathrm{~cm}$ (Fig. 1). Boundary conditions in the overlying water are fixed concentrations for the dissolved species and represent average values in coastal/shelf environments $\left(\mathrm{O}_{2}=350 \mu \mathrm{M}, \mathrm{NO}_{3}{ }^{-}=10 \mu \mathrm{M}\right.$, $\left.\mathrm{NH}_{4}{ }^{+}=3 \mu \mathrm{M}, \mathrm{SO}_{4}{ }^{2-}=28000 \mu \mathrm{M}, \mathrm{S}^{2-}=0 \mu \mathrm{M}\right)$. A zero flux condition is imposed at the base of the model sediment (i.e. at $15 \mathrm{~cm}$ depth). Note that there are no boundary conditions for TOC because TOC is not modeled - sedimentary TOC concentrations are imposed. This means that sediment mixing, by either bioturbation or hydrodynamics, is not necessary in this model setup (i.e. the model is applied to non-bioturbated sediments). The imposed sediment depth profile of TOC concentrations in the model is that commonly observed in marine sediments (i.e. an exponential function of depth with concentrations rapidly decreasing away from the SWI, e.g. Lohse et al. 1998). It is assumed that $0.6 \%$ of the TOC is available for breakdown at the SWI and $0.2 \%$ is available beyond approximately $3 \mathrm{~cm}$ depth (Nedwell 1987). Organic carbon content is assumed to be $1 \%$ at the sediment surface. The molar carbon to nitrogen $(\mathrm{C}: \mathrm{N})$ ratio of sedimentary organic matter is highly variable (e.g. 6 to 56, Nedwell \& Trimmer 1996, Lohse et al. 1998, Rys- 


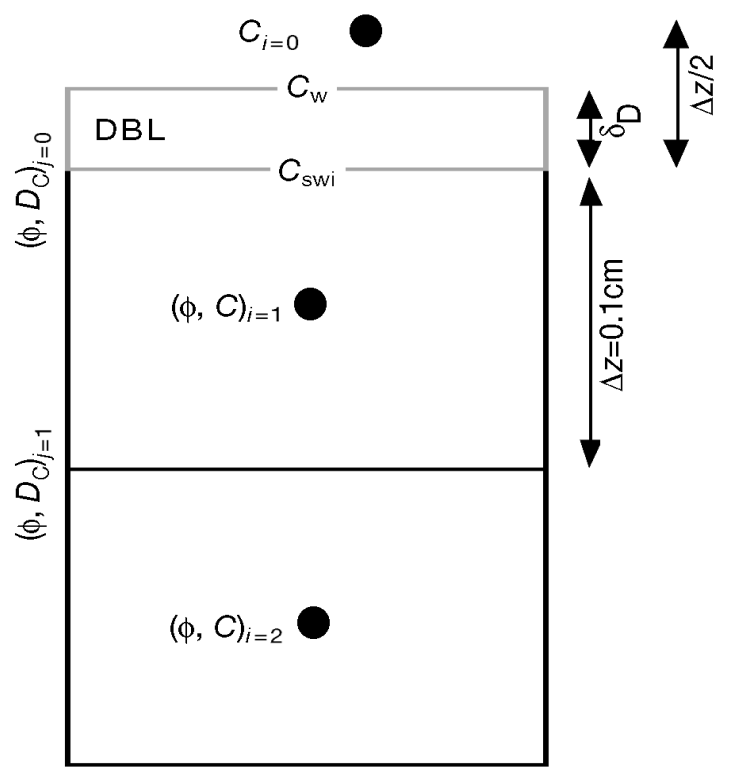

Fig. 1. Numerical grid incorporating the diffusive boundary layer (DBL). Note that only the top 2 grid cells are shown for clarity (actual model domain contains 150 grid cells). $i, j$ : numerical grid indices; $C$ : modelled solute concentration; $\Delta z$ : grid cell size; $C_{\mathrm{w}}$ : concentration of solute in overlying turbulent flow region; $C_{\text {swi }}$ : solute concentation at sediment water interface; $D_{\mathrm{C}}$ : diffusion coefficient; $z$ : depth in sediment; $\phi$ : porosity; $\delta_{\mathrm{D}}$ : diffusive sublayer thickness

gaard et al. 2001) and is not necessarily an indicator of degradability (Lohse et al. 1998). A value of 15 is set (DBL sensitivity to changes in the value of the $\mathrm{C}: \mathrm{N}$ ratio in the model were found to be negligible, data not shown). Organic carbon reactivity is determined by a first order rate constant $(k)$ which is used to simulate all pathways of organic carbon degradation. The use of one $k$ for all mineralisation pathways combined with the decreasing organic carbon concentrations with depth is equivalent to the formulation $k=k_{0} \mathrm{e}^{-\mathrm{az}}$, where $k_{0}$ is the value of the rate constant at the SWI, $\alpha$ is the coefficient of decrease and $z$ is depth as tested in Kelly-Gerreyn et al. (1999). Kelly-Gerreyn et al. (1999) found that this parameterisation over-predicted rates of denitrification in high nitrate environments (e.g. up to $1200 \mu \mathrm{M}$, the Gt. Ouse, UK, Nedwell \& Trimmer 1996). The nitrate concentration imposed in the overlying water in this model application is low $(10 \mu \mathrm{M})$ compared to such high values observed in UK estuaries. Temperature effects on biogeochemical reactions (i.e. $Q_{10}$ effects) are ignored, as this work does not focus on seasonal sedimentary dynamics, in contrast to Kelly-Gerreyn et al. (2001). Porosity at any depth $z$ is described by an equation of the form:

$$
\phi_{z}=\phi_{\infty}+\left(\phi_{0}-\phi_{\infty}\right) \mathrm{e}^{-\left(z / \phi_{\text {coeff }}\right)} \quad \text { (Berner 1980) }
$$

where $\phi_{0}$ is the surface porosity $(0.99), \phi_{\infty}$ is the porosity at depth (0.85) and $\phi_{\text {coeff }}$ is the coefficient describ- ing the exponential decrease in porosity with depth (e.g. $\left.\phi_{\text {coeff }}=4\right)$. These values are similar to those used by Soetaert et al. (1996) and typical for many sediments. All other details (assumptions, equations and parameters) can be found in Kelly-Gerreyn et al. (1999). Only details of the implementation of the DBL and 2 examples of the model equations are described hereafter.

It is assumed that no biogeochemical processes occur within the DBL. Hence, mass continuity requires that the concentration gradient through the sublayer is equal to that across the SWI yielding a boundary condition satisfying:

$$
-\left[\phi \frac{\partial C}{\partial z}\right]_{z=0}=\frac{\left(C_{\mathrm{w}}-C_{0}\right)}{\delta_{\mathrm{D}}} \quad \text { (Boudreau 1997) }
$$

where $C_{\mathrm{w}}$ is the concentration of the solute in the overlying turbulent flow region, $C_{0}$ is the concentration at the SWI, $\phi$ is the porosity, $z$ is depth in the sediment and $\delta_{\mathrm{D}}$ is the diffusive sublayer thickness. The numerical scheme adopted in Kelly-Gerreyn et al. (1999) is used in the following description of the implementation of the DBL. All model layers (grid cells), each of equal length $\Delta z$, are defined by an $i$-index located in the middle of a cell (Fig. 1). Solute concentrations are modelled at these $i$ locations (the centre of each grid cell). The $i$ indices run from 1 at the top of the sediment to 150 at the bottom, yielding a total sediment depth of 15 $\mathrm{cm}$. The interfaces between cells, including the SWI, are defined by a $j$-index which runs from 0 (the SWI) to 150 (the lower boundary of cell $i=150$ ). Porosities are defined both at $i$ and $j$ indices (from Eq. 1) while sediment diffusion coefficients are defined only at $j$ positions. Note that $\phi_{0}$ in Eq. (1) is the porosity value in the first sediment layer (i.e. at $i=1$, not at $j=0$ where by convention $\phi=1)$.

At the $\operatorname{SWI}(j=0, \phi=1)$, Eq. (2) is discretised according to Boudreau (1997) to give:

$$
C_{-1}=C_{1}+\frac{\Delta z}{\delta_{\mathrm{D}}}\left(C_{\mathrm{w}}-C_{0}\right)
$$

where $C_{1}$ is the concentration in the top grid cell of the model domain ( $i=1$, Fig. 1 ) and $C_{-1}$ is the concentration at an imaginary point $(i=-1)$ at $z=-\Delta z / 2(\Delta z$ is the grid cell thickness $=0.1 \mathrm{~cm}$, Fig. 1 ) and

$$
C_{0}=C_{1}+\frac{\frac{\Delta z}{2}}{\left(\delta_{\mathrm{D}}+\frac{\Delta z}{2}\right)}\left(C_{\mathrm{w}}-C_{1}\right)
$$

It can be seen that as $\delta_{\mathrm{D}}$ approaches $0, C_{0}$ approaches $C_{\mathrm{w}}$. Eq. (3) can thus be substituted into the discretised form of the reaction-diffusion equation used in the model (see Eq. A2 in Appendix A in KellyGerreyn et al. 1999) to give the rate of change of a dissolved substance in the top grid cell ( $i=1$ and $j=0$, Fig. 1) as: 
Rate of change $=$

$$
-\phi_{j} D_{\mathrm{C}_{j}} \frac{\left(\frac{\Delta z}{\delta_{\mathrm{D}}}\left(C_{0}-C_{\mathrm{w}}\right)\right)}{\phi_{i} \Delta z^{2}}+\phi_{j+1} D_{\mathrm{C}_{j+1}} \frac{\left(C_{i+1}-C_{i}\right)}{\phi_{i} \Delta z^{2}}+\Sigma R_{i}
$$

where $D_{\mathrm{C}}$ is the diffusion coefficient corrected for temperature (arbitrarily taken as $10^{\circ} \mathrm{C}$ : this has no impact on the model outcome as only changes in DBL thicknesses are examined here) and tortuosity (Eq. 4 in Kelly-Gerreyn et al. 1999) and $R$ is the set of reaction terms that includes organic decay (Eqs. 7 to 11 in Kelly-Gerreyn et al. 1999, in which the first order rate constants for organic decay are the same for all pathways of organic carbon mineralisation). For example, the rates of denitrification and nitrification are mathematically expressed as:

$$
k[\text { TOC }]\left(\frac{\mathrm{NO}_{3}}{\mathrm{NO}_{3}+K \mathrm{~s}_{\mathrm{NO}_{3}}}\right)\left(1-\frac{\mathrm{O}_{2}}{\mathrm{O}_{2}+K \mathrm{~s}_{\mathrm{inhO}_{2}}}\right) \text { (dentrification) }
$$

and

$$
K_{\text {nit }}\left[\mathrm{NH}_{4}\right]\left(\frac{\mathrm{O}_{2}}{\mathrm{O}_{2}+K \mathrm{~S}_{\mathrm{limO}_{2}}}\right) \text { (nitrification) }
$$

where $k$ is the first order rate constant for organic decay (see 'Scenarios and model runs'), TOC is total organic carbon concentration, $\mathrm{NO}_{3}$ and $\mathrm{O}_{2}$ are the nitrate and oxygen concentrations, respectively, $\mathrm{KS}_{\mathrm{NO}_{3}}$ is the half saturation constant for nitrate limitation (30 $\mathrm{MM} \mathrm{NO}_{3}{ }^{-}$), $\mathrm{Ks}_{\mathrm{inhO}_{2}}$ is the half saturation constant for oxygen inhibition $\left(6.25 \mu \mathrm{M} \mathrm{O}_{2}\right), K_{\text {nit }}$ is the first order rate constant for nitrification $\left(12520 \mathrm{yr}^{-1}\right), \mathrm{NH}_{4}$ is the ammonium concentration and $\mathrm{Ks}_{\mathrm{limO}_{2}}$ is the half saturation constant for oxygen limitation in nitrification $\left(1 \mu \mathrm{M} \mathrm{O}_{2}\right.$ ). To convert from carbon units to nitrogen units, Eq. (6) is multiplied by the stoichiometric ratio 0.8 (mole of nitrate reduced per mole of carbon oxidised: see Table 1 legend for other stoichiometric ratios for refer to Kelly-Gerreyn et al. (1999). The first fraction term in Eq. (6) and the fraction term in Eq. (7) are Michaelis-Menten type formulations expressing the limitation on the rate (e.g. oxygen limitation on nitrification in which the degree of limitation is determined by the numeric value of $\mathrm{KS}_{\mathrm{limO}_{2}}$ ). The same oxygen limitation function in Eq. (7) is applied to sulphide reoxidation. The second fraction term in Eq. (6) is an inhibition function in which the degree to which denitrification is inhibited by the presence of oxygen is determined by the numeric value of $K \mathrm{~s}_{\text {inhO}_{2}}$. A similar equation to Eq. (6) exists for sulphate reduction which is co-inhibited by both nitrate and oxygen. Use of inhibition and limitation functions allows processes to overlap within the same sediment layer and is the mechanism by which the depth stratified series of biogeochemical zones observed in nature can be simulated. Such formulations (and the associated parameter values) are standard in early diagenetic models (e.g. Soetaert et al. 1996, Boudreau 1997, Kelly-Gerreyn et al. 1999, 2001).

Scenarios and model runs. Five scenarios were investigated in which oxygen respiration dominates the breakdown of organic carbon (Table 1). A different value of the first order rate constant for organic carbon mineralisation was used in each scenario $(k=1,5,10$, $\left.20,40 \mathrm{yr}^{-1}\right)$, which represents the range found in nature $\left(0.005\right.$ to $53 \mathrm{yr}^{-1}$, Andersen $1996 ;<1$ to $22.6 \mathrm{yr}^{-1}$, Lohse et al. 1998). A range in thickness of the DBL $(0.0001$ to $0.1 \mathrm{~cm}$ ) was imposed in each scenario. The quantification of the change in model quantities (e.g. oxygen flux across the SWI) with respect to changes in the DBL thickness is calculated by comparison with a reference run. The reference run for each scenario was the model output in which the DBL $=0.0001 \mathrm{~cm}$ (Table 1). Lower values of the DBL had a negligible impact on the model (note that Eq. 2 precludes the use of $\delta_{\mathrm{D}}=0$ ).

The dependency of the DBL thickness on the solute (Eqs. 8 \& 9, see below) means that sublayer thicknesses vary by less than $10 \%$ among the model variables (calculations based on using appropriate diffusion coefficients for 
each variable). These differences in thickness had a negligible effect on the results (not shown). It was assumed that the thickness of the DBL was the same for each variable.

The model was run to a new steady state for each thickness of the DBL in the range 0.01 to $0.1 \mathrm{~cm}$.

\section{RESULTS}

\section{Porewater profiles}

Changes in the oxygen porewater profiles in response to variations in the thickness of the DBL for the 5 scenarios are shown in Fig. 2a to e. An increase in the thickness of the DBL decreased both oxygen penetration and concentrations in the sediment. The effect of larger $k$ values was to decrease the OPD (Fig. 2a to e) because higher values yielded higher rates of oxygen consumption in the model (Table 1).

Porewater profiles of nitrate (Fig. 2f to j) and sulphate (Fig. 2k to o) responded to increased sublayer thicknesses in a similar way to oxygen (Fig.2a to e). Thicker DBLs yielded lower nitrate and sulphate concentrations in the sediment. The effect of increasing the value of $k$ decreased the penetration of nitrate, with values of $k \leq 20 \mathrm{yr}^{-1}$ yielding nitrate maxima in the top $1 \mathrm{~cm}$ (Fig. 2f to j) indicative of nitrification. An increase in the DBL thickness increased the sedimentary concentration of ammonium in each scenario as did increases in value of $k$ (Fig. $2 p$ to $t$ ).
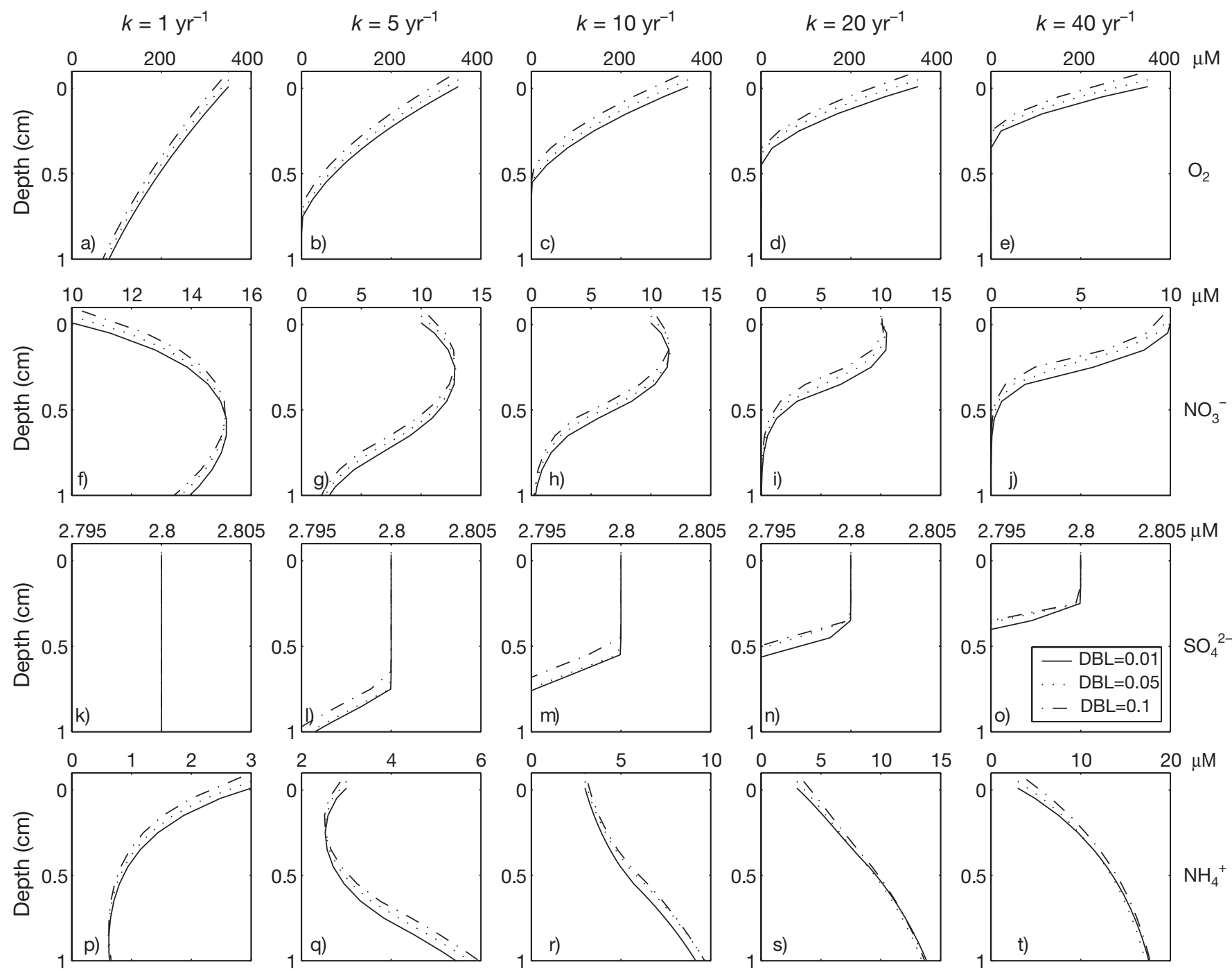

Fig. 2. Effect of changes in the DBL thickness on porewater concentration profiles of $(a-e)$ oxygen, $(\mathrm{f}-\mathrm{j})$ nitrate, $(\mathrm{k}-\mathrm{o}) \mathrm{sulphate} \times$ $10^{-4}$ and $(\mathrm{p}-\mathrm{t}$ ) ammonium in Scenarios 1 to 5. (Note only results for 3 DBL thicknesses [cm] in the upper $1 \mathrm{~cm}$ of sediment plotted for clarity; concentration in $\mu \mathrm{M}$; zero depth = sediment water interface (SWI); negative depths represent the DBL) 


\section{SWI fluxes}

The percentage changes in fluxes of oxygen, nitrate, ammonium and sulphate across the SWI in response to different thicknesses of the DBL in each scenario are shown in Fig. 3a to d. Oxygen fluxes decreased relative to the reference runs, with increasing thicknesses in the DBL in each scenario (Fig. 3a). The larger the value of $k$, the greater the reduction in the oxygen flux. Oxygen fluxes decreased by between 5 and $22 \%$ for a DBL thickness of $0.1 \mathrm{~cm}$. The nitrate flux decreased with increasing DBL thicknesses in all scenarios except scenario $5\left(k=40 \mathrm{yr}^{-1}\right)$. The flux of nitrate was directed out of the sediment in Scenarios 1 to 4 and into the sediment in Scenario 5 (Table 1) as indicated by the nitrate porewater profiles (Fig. 2f to j). For Scenarios 1 to 4 , the larger the $k$ value, the greater the reduction in efflux (Fig. 3b). Nitrate effluxes decreased by less than $30 \%$ for $k \leq 10 \mathrm{yr}^{-1}$ and decreased by $90 \%$ for $k=20 \mathrm{yr}^{-1}$. In contrast, the nitrate flux in Scenario 5 (a flux into the sediment) increased by $380 \%$ for the maximum imposed DBL thickness $\left(k=40 \mathrm{yr}^{-1}\right.$, Fig. 3b). The flux of ammonium
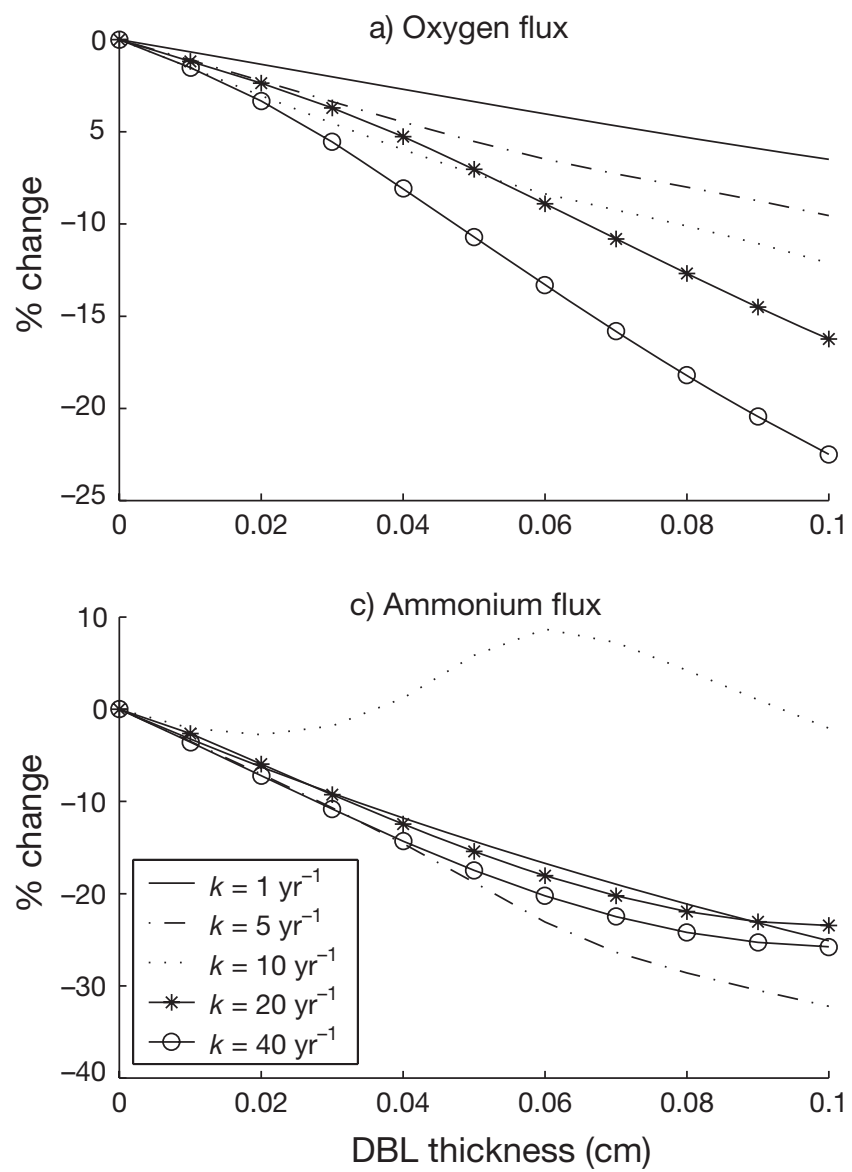

decreased by between 20 and $30 \%$ in Scenarios 1, 2, 4 and 5 with increasing sublayer thickness (Fig. 3c). In contrast, the ammonium flux decreased slightly $(<2 \%)$ for DBL $\leq 0.04 \mathrm{~cm}$ and then increased (by $\leq 8 \%$ ) for thicker DBLs in Scenario 3, reaching a maximum at a DBL of $0.06 \mathrm{~cm}$. Sulphate fluxes decreased by between 30 and $>99 \%$ in response to thicker DBLs (Fig. 3d). Note that sulphate fluxes were small (order $10^{-5} \mathrm{~mol} \mathrm{~m}^{-2} \mathrm{yr}^{-1}$, Table 1).

\section{Sedimentary processes}

The effects of variations in the thickness of the DBL on sedimentary processes (total carbon oxidation, oxygen respiration via organic carbon mineralisation, denitrification, sulphate reduction, nitrification, sulphide reoxidation and ammonification) are shown for each scenario in Fig. 4a to g. Rates of total carbon oxidation decreased with increasing DBL thicknesses in all scenarios (Fig. 4a). The higher the value of $k$, the greater the decrease in carbon oxidation. Hence, the greatest reduction of $22 \%$ occurred in Scenario $5\left(k=40 \mathrm{yr}^{-1}\right)$.
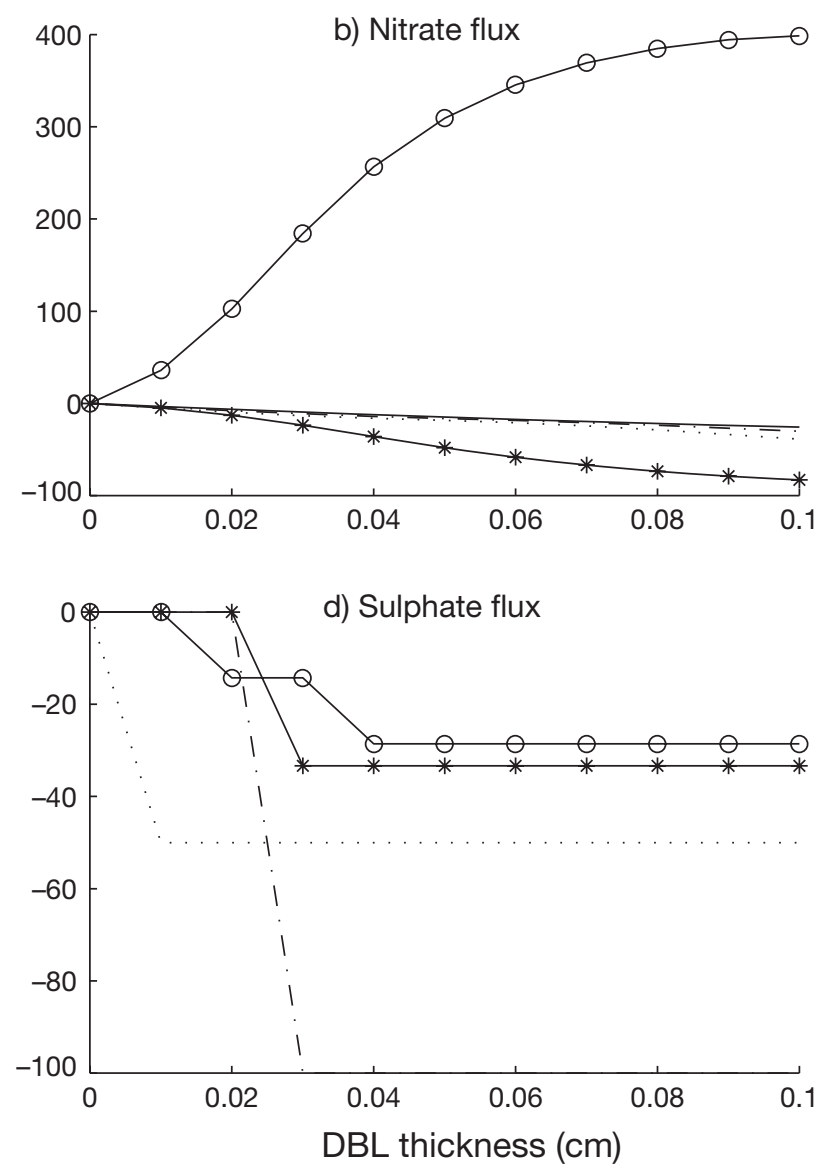

Fig. 3. Effect of changes in the DBL thickness on solute fluxes across the SWI in Scenarios 1 to 5 (see 'Scenarios and model runs' for details; percentage change is relative to the standard run in which the DBL thickness $=0.0001 \mathrm{~cm}$ ) 

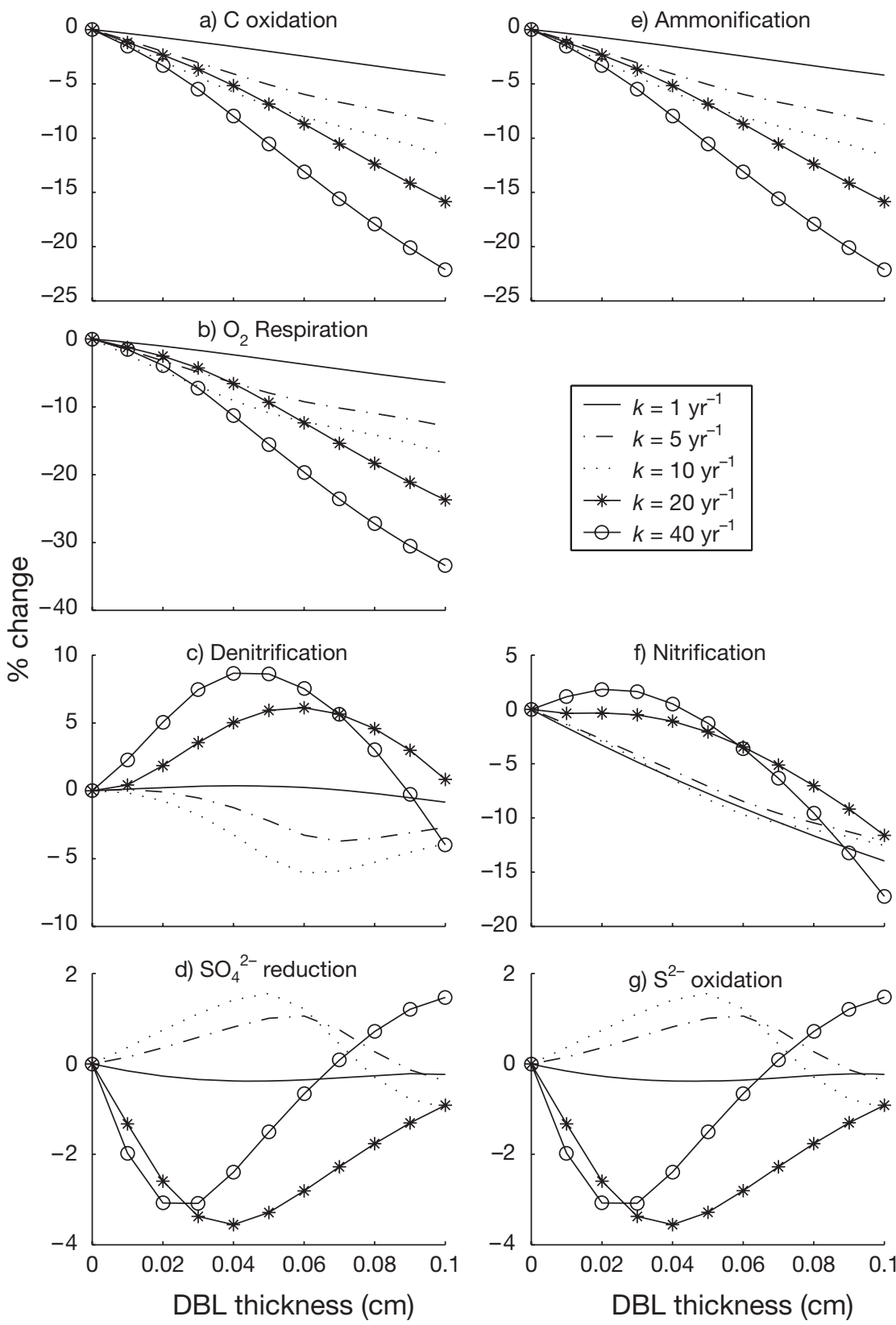

$$
\begin{aligned}
& -k=1 \mathrm{yr}^{-1} \\
& -k=5 \mathrm{yr}^{-1} \\
& \cdots \quad k=10 \mathrm{yr}^{-1} \\
& * \quad k=20 \mathrm{yr}^{-1} \\
& -k=40 \mathrm{yr}^{-1}
\end{aligned}
$$
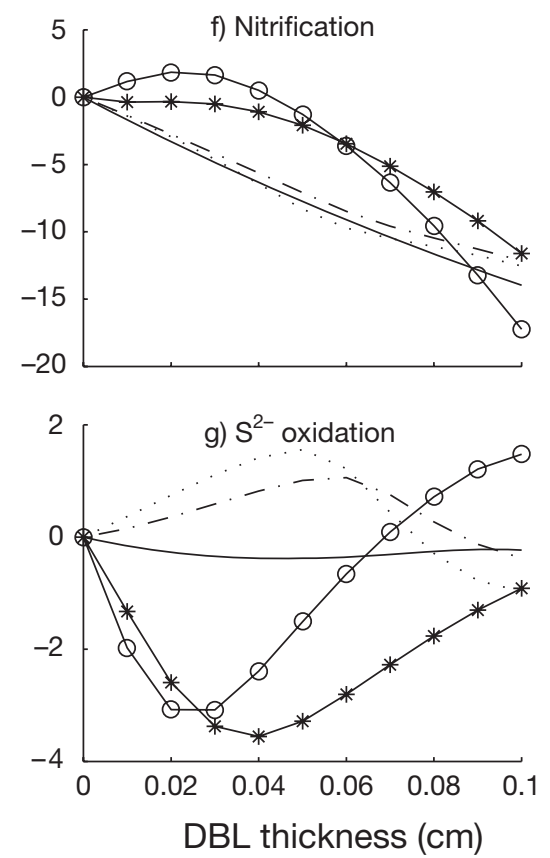

Fig. 4. Effect of changes in the DBL thickness on modeled sedimentary processes in Scenarios 1 to 5 (see 'Scenarios and model runs' for details; percentage change is relative to the standard run in which the DBL thickness $=0.0001 \mathrm{~cm}$ )

Oxygen respiration rates (oxic mineralisation) responded in a similar way to changes in the DBL. The maximum reduction ( $33 \%$ ) occurred at $\mathrm{DBL}=0.1 \mathrm{~cm}$ in Scenario 5. The responses of both total carbon mineralisation and oxygen respiration followed the response of the oxygen fluxes to changes in the DBL (Fig. 3a). That is, a reduction in the flux of oxygen reduced the supply for oxic mineralisation. Since oxic mineralisation contributes significantly to the sum of total organic matter degradation (>60\%, Table 1$)$, a decrease in oxic mineralisation had a significant effect on total carbon oxidation (Fig. 4a). Consequently, a high contribution of oxic mineralisation to total organic matter oxidation yields a high sensitivity of the latter to variations in the DBL. Also, the higher the reactivity of the organic carbon (i.e. higher $k$ ), the greater the response to changes in the DBL thickness. This is because higher reactivity yielded higher rates of oxygen consumption which resulted in lower OPD (Fig. 2f). Lower OPD means that a greater proportion of the oxygen concentration versus sediment depth profile is contained within the DBL. Consequently, more of the diffusion time occurs in the DBL which explains the increased influence of the DBL on oxygen fluxes as the reactivity of the TOC increases.

Rates of denitrification responded differently to changes in DBL thicknesses among the scenarios (Fig. 4c). Denitrification rates decreased non-linearly across the range in DBL thicknesses in Scenarios 1 to $3\left(k \leq 10 \mathrm{yr}^{-1}\right)$ relative to the reference runs. In contrast, rates of denitrification increased non-linearly in response to thicker DBLs in Scenarios 4 and 5 and in Scenario 5 for DBL $\geq 0.09 \mathrm{~cm}$, the rate of nitrate reduction decreased relative to the reference run. The higher the $k$ value, the greater the maximum change in denitrification rates. All changes were within $\pm 8 \%$ (Fig. 4c). Rates of nitrate reduction were fuelled by nitrate derived from nitrification in all scenarios. Rates of nitrification were not sufficient to supply all of the denitrification demand in Scenario 5. Consequently, nitrate from the overlying water made up for the deficit as shown by the nitrate flux into the sediment (Table 1).

Rates of sulphate reduction changed by $<3 \%$ in all scenarios for all DBL thicknesses (Fig. 4d). These responses are explained in connection with sulphide oxidation (see below).

The response of rates of ammonification to changes in the DBL thickness (Fig. 4e) were, unsurprisingly, the same as those of organic carbon oxidation (Fig. 4a) higher TOC reactivities (larger $k$ ) were impacted to a greater extent than lower reactivities by changes in the DBL. This similarity results from the fact that ammonium production is proportional to organic carbon 
oxidation in the ratio 16:106 (standard stoichiometry). This decrease in ammonification is paradoxical when set against the increase in concentrations of ammonium in the upper porewaters in all scenarios (Fig. $2 p$ to r). To understand this, it is important to consider that the diffusion path length increases through the DBL as the latter thickens. The effect of this is best illustrated by considering the behaviour of a tracer affected only by diffusion across a particular depth interval. An increase in the depth interval (as caused by a thicker DBL) changes the concentration gradient of the tracer (note that the top boundary concentration remains the same, irrespective of the DBL thickness). This mostly reduces the diffusive flux through the sediment (Fig. 3c, Scenarios 1, 2, 4 and 5) and hence changes the sedimentary tracer concentration between the 2 horizons depending on the direction of the flux. Consequently, in response to increasing DBL thicknesses, ammonium concentrations increased in the upper few millimetres when the gradient favoured an efflux (Scenarios 3 to 5, Table 1) - although depth integrated ammonification throughout the model sediment domain decreased (Fig. 4e)-and the ammonium concentrations decreased when the gradient favoured a flux into the sediment (Scenarios 1 to 2). In the case of the increase in ammonium fluxes with increasing DBL thicknesses (Scenario 3, Fig. 3c), this results from the steep gradient in the ammonium concentration across the sediment water interface (Fig. 2r). A value of $k=10 \mathrm{yr}^{-1}$ represents the model state close to which lower values create a flux of ammonium into the sediment and higher values yield an efflux (Table 1). Such a model state is mathematically referred to as an inflexion point and is the state which will yield the steepest (vertical) concentration gradient for ammonium. In this case, ammonium fluxes will be zero. Consequently, changes in the concentration gradient away from this inflexion point (or from a point very close to it, as in Scenario 3) caused by changes in the DBL thickness explain the increase in the ammonium flux in Scenario 3 (Fig. 3c). Reductions in the ammonium efflux may limit rates of primary production in areas where the majority of the nitrogen required by phytoplankton is regenerated in the sediments (Fisher et al. 1982, Cowan et al. 1996).

Rates of nitrification decreased in response to increasing DBL thicknesses in Scenarios 1 to 5 (Fig. 4f) by a maximum of between 15 and $18 \%$. This decrease was driven by the reduction in oxygen concentrations in the sediments (Fig. 2a) and by the decrease in ammonium production (Fig. 4e). The increase in nitrification rates for DBL thicknesses $<0.05 \mathrm{~cm}$ when $k=40 \mathrm{yr}^{-1}$ (Scenario 5) resulted from increases in sedimentary concentrations of ammonium (Fig. 2d) which were high enough to counter the limiting effects of lower oxygen concentrations (see Eq. 7). This increase in nitrification, plus the lowering of oxygen concentrations due to thicker DBLs, explain the increase in denitrification rates modelled in Scenario 5 (Fig. 4c) - note that the half saturation constant for oxygen inhibition in denitrification is higher $\left(K \mathrm{~s}_{\mathrm{inhO}_{2}}=\right.$ $6.25 \mu \mathrm{M}$ ) than the half saturation constant for oxygen limitation in nitrification $\left(K \mathrm{~s}_{\mathrm{limO}_{2}}=1 \mu \mathrm{M}\right)$ (see 'Model description'). This enhancement of denitrification explains the increase in nitrate flux to the sediment with increasing DBL thickness in Scenario 5 (Fig. 3b). The decline in denitrification rates for DBL $>0.04 \mathrm{~cm}$ in Scenario 5 (Fig. 4c) results from the reduced supply of nitrate caused by the decrease in nitrification rates (Fig. 4f). The lack of decrease in the nitrate flux in Scenario 5, given that the demand by denitrification decreased for DBLs thicker than $0.04 \mathrm{~cm}$, was the result of rates of nitrification decreasing by a greater extent (owing to intense oxygen limitation) compared to rates of denitrification. Consequently, rates of denitrification remained higher than rates of nitrification (Table 1), meaning that there was still a demand for nitrate from the overlying water for all values of the DBL (Fig. 3b). The increase in denitrification rates for DBL $<0.07 \mathrm{~cm}$ in Scenario $4(k=$ $20 \mathrm{yr}^{-1}$ ) resulted from reduced oxygen inhibition while rates of nitrification remained only marginally limited by oxygen; oxygen concentrations were between $1 \mu \mathrm{M}$ (the limiting concentration for nitrification, $K_{\mathrm{limO}_{2}}$, see 'Model description') and 6.25 $\mu \mathrm{M}$ (the concentration below which inhibition on denitrification is lifted, $\mathrm{Ks}_{\mathrm{inhO}_{2}}$ ). Once concentrations of oxygen became more limiting $(<1 \mu \mathrm{M})$, nitrification rates reduced by a greater extent with increasing DBL $(>0.07 \mathrm{~cm})$ in Scenario 4 . The lowering of denitrification rates in Scenarios 1 to 3 (Fig. 4c) is explained by the fact that nitrification rates were more sensitive to increases in DBL thicknesses as a result of lower ammonium production compared to Scenarios 4 $\left(k=20 \mathrm{yr}^{-1}\right)$ and $5\left(k=40 \mathrm{yr}^{-1}\right)$ (Table 1$)$.

Sulphide oxidation (Fig. 4g) responded in an identical way to sulphate reduction (Fig. 4d) and changed by $<3 \%$ in response to increases in the DBL in all Scenarios. The response of sulphide oxidation rates is connected to the fact that this process competes with nitrification for oxygen (the limitation term, shown in Eq. 7, for both processes is the same). As rates of nitrification decreased, in response to thicker DBLs (Fig. 4f), oxygen utilisation via nitrification decreased which left more oxygen for use via sulphide oxidation. Hence, the balance of oxygen usage between nitrification and sulphide oxidation explains the increase in sulphide oxidation in Scenarios 1 and 2 and the decrease in sulphide oxidation in Scenarios 4 and 5. It is this balance which drives the model response of sulphate reduction to changes in DBL thicknesses (Fig. 4d) - note that sulphate reduction is fuelled by sulphide oxidation rather than by incoming sulphate fluxes from the overlying water (Table 1). 


\section{DISCUSSION}

At steady state, the benthic flux is balanced by the integrated reaction rate over the sediment depth. In the model presented here, only the DBL thickness was changed between runs. The concentration of organic matter in the model sediment and the boundary conditions were the same for each Scenario between model runs. Hence. it is not surprising that changes in the diffusive sublayer thickness (which alters the diffusion time through the DBL) influenced the reaction rates in the sediment. Furthermore, an increase in the diffusive sublayer thickness increased the proportion of the oxygen concentration gradient that is contained within the DBL (Fig. 2a,b). This explains why increases in DBLs had an enhanced impact on oxygen fluxes and mineralisation rates. The narrower the oxic layer relative to the thickness of the DBL, the greater the control of the DBL on solute exchange at the SWI because more of the diffusion time occurs in the DBL compared to the sediment. These effects support the predictions of Archer et al. (1989).

Thinner oxic layers increased rates of denitrification (Fig. 4c) and sulphate reduction (Scenario 1, Fig. 4d) which fuelled the increases in fluxes of nitrate (Fig. 3b) and sulphate (Scenario 1, Fig. 3d). Such changes in sediment depth-integrated anoxic carbon oxidation rates occurred as a result of increases in these rates in the upper sediment (not shown). Changes in rates of denitrification and sulphate reduction in response to changes in the DBL were negligible at greater sediment depths. This means that increases in modelled anaerobic respiration rates were fuelled by the reduced oxygen concentrations that occur in the surface sediments (Fig. 2a,b) rather than by any direct effects of thickening DBLs.

The predicted effects of the DBL on rates of total organic matter oxidation, rates of denitrification and benthic fluxes can have implications for nutrient and carbon budgets. For instance, changes in rates of organic degradation can influence the preservation of organic matter in sediments although other factors may be more important (Hedges \& Keil 1995). Hedges \& Keil (1995) concluded that $45 \%$ of organic matter inputs are preserved on shelf sediments which contrasts with more recent calculations, suggesting that shelf seas play only a minor role in the preservation and withdrawal of organic carbon from the global carbon cycle (de Haas et al. 2002). In either case, the presence of a diffusive sublayer may increase the organic carbon preservation capability of shelf sea sediments. For instance, the major region of organic carbon accumulation in the southern North Sea (Fig. 2 in de Haas et al. 2002) is the same area where oxygen consumption is dominated by the oxidation of organic carbon
(Upton et al. 1993, Slomp et al. 1997), where oxygen penetration can be less than $0.1 \mathrm{~cm}$ (Lohse et al. 1996) and where weak tidal currents and infrequent mobilisation of the sediment occur (Site B in Williams et al. 1998). It is possible to calculate a likely range in DBL thicknesses in this region from:

$$
\delta_{\mathrm{D}}=5 \mathrm{Sc}^{-1 / 3} v / u_{*} \quad(\text { Dade et al. 2001) }
$$

where $v$ is the kinematic viscosity $\left(=0.01 \mathrm{~cm} \mathrm{~s}^{-1}\right.$, Boudreau 1997), $u_{*}$ is the near-bed current shear velocity ( 0.1 to $0.81 \mathrm{~cm} \mathrm{~s}^{-1}$ measured in September 1989 at Site B in Williams et al. 1998) and Sc is the Schmidt number $(=v / D$, Sideman \& Pinczewski 1975 quoted in Boudreau [1997] where $D$ is the temperature corrected free solution diffusion coefficient). To calculate $D$ for oxygen at ambient temperature, the equation and parameter values from Soetaert et al. (1996) are used:

$$
D=\left(D^{0}+D^{\text {const }} \cdot T\right)
$$

where $D^{0}$ is the $0^{\circ} \mathrm{C}$ free solution diffusion coefficient for oxygen $\left(1.1 \times 10^{-5} \mathrm{~cm}^{2} \mathrm{~s}^{-1}\right), D^{\text {const }}$ is an ion-specific constant for oxygen $\left(4.47 \times 10^{-7} \mathrm{~cm}^{2} \mathrm{~s}^{-1}{ }^{\circ} \mathrm{C}^{-1}\right)$ and $T$ is the mean temperature $\left(10^{\circ} \mathrm{C}\right.$ in September 1989, Upton et al. 1993). Substituting Eq. (9) into Eq. (8) yields a DBL thickness of 0.007 to $0.06 \mathrm{~cm}$. In measuring the benthic oxygen consumption rates in this area, Upton et al. (1993) averaged their measurements over a range of stirring speeds greater than $300 \mathrm{rpm}$. Such speeds are greater than that needed to suppress the DBL (Glud et al. 1996). Although Upton et al. (1993) did not measure oxygen consumption due to iron and manganese reoxidation, Slomp et al. (1997) concluded that this was an insignificant component of benthic oxygen demand in the southern North Sea. Consequently, results from this modelling study make it possible to speculate that a neglect of the DBL may overestimate oxygen fluxes and total carbon oxidation rates by no more than $13 \%\left(\delta_{\mathrm{D}}=0.05\right.$ in Scenario 5, Figs. 3a \& 4a) in these carbon accumulating sediments of the southern North Sea. This effect does not implicate the DBL as a major factor in organic carbon preservation in North Sea sediments. This finding supports the conclusions of Jørgensen \& Boudreau (2001). Consequently, the potential of the DBL to control benthic fluxes and to promote carbon preservation is likely to be greater in sediments over which thicker DBLs occur (because of low enough near-bed current velocities) and which are fine-grained, have low permeability $\left(<10^{-12} \mathrm{~m}^{-2}\right.$, Huettel et al. 2003) and are non-bioirrigated. An example is Southampton Water (UK), where the sediments are predominantly muddy (Velegrakis 2000), are dominated by non-irrigating, filter feeding, surface- 


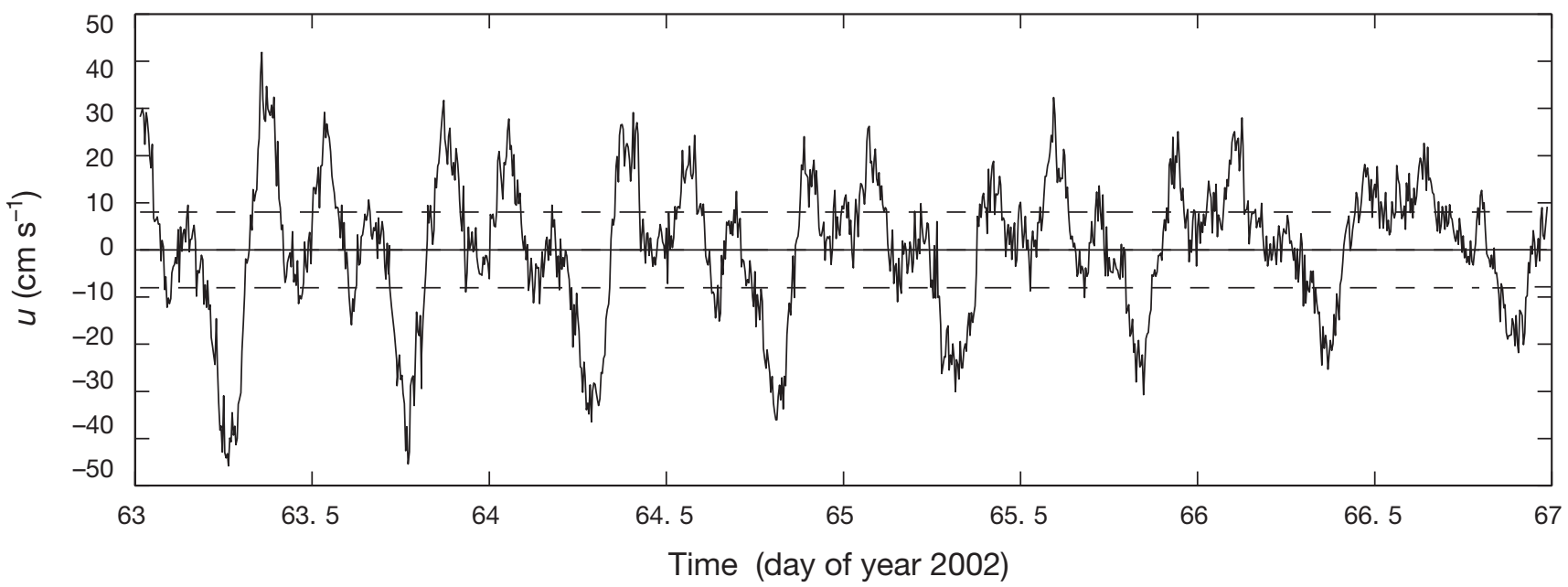

Fig. 5. A $4 \mathrm{~d}$ snapshot of near-bed current velocity amplitudes $\left(u, \mathrm{~cm} \mathrm{~s}^{-1}\right)$ at $75 \mathrm{~cm}$ above the seabed in Southampton Water (mean water depth $10 \mathrm{~m}$ ) measured using a $1200 \mathrm{kHz}$ Acoustic Doppler Current Profiler (ADCP) deployed in an upward looking configuration from January to April 2002. This 4 d subsample of the full data set includes the annual maximum springtide. The solid, white horizontal line indicates the velocities $\left(\leq 8 \mathrm{~cm} \mathrm{~s}^{-1}\right)$ for which DBLs can become established (see text for details)

dwelling fauna (Crepidula fornicata, Ostrea edulis) (Collins \& Mallinson 2000) and near-bed current velocities (Fig. 5) are, for a significant period of time (31\% of the $\sim 3.5$ mo sampling period), close to values for which DBLs in the range 0.016 to $0.12 \mathrm{~cm}$ have been determined (0.3 to $7.7 \mathrm{~cm} \mathrm{~s}^{-1}$, Jørgensen \& Des Marais 1990; 2.4 to $6 \mathrm{~cm} \mathrm{~s}^{-1}$, Glud et al. 1995; 2.0 and $8.0 \mathrm{~cm} \mathrm{~s}^{-1}$, Santschi et al. 1991). The current velocities quoted in Jørgensen \& Des Marais (1990) and Glud et al. (1995) were measured at $1 \mathrm{~cm}$ above and within $10 \mathrm{~cm}$ of the SWI, respectively, while Santschi et al. (1991) relied on values estimated at $100 \mathrm{~cm}$ above the seabed. Consequently, the near-bed current velocities $\left(\leq 8 \mathrm{~cm} \mathrm{~s}^{-1}\right)$ in Fig. 5, measured at $75 \mathrm{~cm}$ above the SWI, are more comparable to the values in Santschi et al. (1991) from which DBL thicknesses of 0.05 and $0.12 \mathrm{~cm}$ were determined. It is possible that the current velocities closer to the SWI in Southampton Water may reach the lower end of the values quoted in Jørgensen \& Des Marais (1990) $\left(0.3 \mathrm{~cm} \mathrm{~s}^{-1}\right)$ and Glud et al. (1995) $\left(2.4 \mathrm{~cm} \mathrm{~s}^{-1}\right)$ since current velocities decrease logarithmically within $1 \mathrm{~m}$ of the sediment surface (Dade et al. 2001). At these lower current velocities, a DBL thickness of $0.06 \mathrm{~cm}$ was measured (Jørgensen \& Des Marais 1990, Glud et al. 1995). Tengberg et al. (2004) found a correlation between bed shear velocity $\left(u_{*}\right)$ and the DBL thickness $\left(\mathrm{DBL}=76.18 u_{*}{ }^{-0.933}\right.$ ) from benthic flux chamber studies. Application of this equation to Southampton Water (in which $u_{*}$ is calculated from current velocity $[u, F i g .5]$ using the quadratic friction law, $u_{*}=\left(C_{\mathrm{d}} \cdot u^{2}\right)^{-1 / 2}$, where $C_{\mathrm{d}}$ is the drag coefficient $=$ 0.0025 to 0.0115 , O'Green et al. 1998) yields DBL thicknesses of $>0.02 \mathrm{~cm}$ for $55 \%$ and $>0.04 \mathrm{~cm}$ for $21 \%$ of the sampling period (range: 0.001 to $0.09 \mathrm{~cm}_{\text {; }}$ mean: $0.026 \pm 0.016 \mathrm{~cm})$. These thicknesses are likely to be underestimates owing to uncertainty in determining the actual bed shear velocity from current data measured at $75 \mathrm{~cm}$ above the sediment surface. The 'law of the wall' equation (e.g. Le Roux 2004) for determining vertical profiles of current velocity close to the sediment surface states that current velocities decrease logarithmically towards the sediment surface. This decrease is proportional to the natural logarithm of the ratio of $z$, the distance above the sediment surface of the current velocity, over $z_{0}$, the distance above the sediment surface where the current velocity is zero (also known as the hydraulic/bed roughness or roughness length). Considering $z=75 \mathrm{~cm}$ (i.e. the measurements in Southampton Water) and $z_{0}=0.5 \mathrm{~cm}$ (mean height of bed roughness caused by Crepidula fornicata, P. L. Friend pers. comm.), the value of $u$ at $75 \mathrm{~cm}$ can be orders of magnitude higher than if measured from a point close to $0.5 \mathrm{~cm}$ (note that as $z$ approaches $0.5 \mathrm{~cm}, u$ approaches $0 \mathrm{~cm} \mathrm{~s}^{-1}$ ). Thus, from the quadratic friction law, it would be reasonable to conclude that the calculation of $u_{*}$ from the measured current velocity at $75 \mathrm{~cm}$ overestimates the shear velocity and therefore underestimates the thickness of the DBL. Consequently, data from Southampton Water suggest that non-negligible thicknesses of the DBL can be established. No data exist on sedimentary oxygen budgets or OPDs for this estuary and so it is impossible to conclude that the DBL controls benthic fluxes in this environment. However, this modelling study acts as a caution to future benthic flux studies in regions such as Southampton Water which neglect the presence of the 
DBL without prior data on near-bed current speeds, sedimentary oxygen budgets, OPDs and sediment grain size distribution. This acts as a caveat for carbon budget studies which rely on benthic fluxes measured using incubation methods which alter the in situ hydrodynamics and change the thickness of the diffusive sublayer. This is particularly so for sediments containing high reactivities (i.e. high $k$ ).

Jørgensen \& Boudreau (2001) modeled the effect of the DBL on oxygen fluxes fuelled by reoxidation processes rather than by carbon mineralisation and found that the diffusive flux at the SWI was independent of the oxygen concentration (i.e. the oxygen concentration is not a term in the formulation of the flux across the SWI). Consequently, Jørgensen \& Boudreau (2001) concluded that the DBL had no impact on oxygen fluxes or on organic carbon preservation as the oxygen flux was related to by-product oxidation rather than to organic degradation). To support these theoretical results, Jørgensen \& Boudreau (2001) cited the experimental work of Glud et al. (1994) that showed that as the DBL decreased from 0.046 to $0.036 \mathrm{~cm}$, the diffusive flux of oxygen was increased by only $8 \%$. This apparently low sensitivity of the oxygen flux to changes in the thickness of the DBL is supported by more recent experimental results from Tengberg et al. (2004) which show no systematic changes in oxygen fluxes with DBL thicknesses in the range 0.012 to $0.056 \mathrm{~cm}$. However, this insensitivity contrasts with data presented in other work (e.g. Huettel et al. 2003, Lorke et al. 2003) showing that oxygen fluxes can be controlled by changes in the DBL in a wider range of thicknesses (e.g. 0.016 to $0.084 \mathrm{~cm}$, Lorke et al. 2003). The model presented here produced a similar change in the oxygen flux $(<10 \%$, Fig. 3a) for changes in the DBL thickness of the same order as in Glud et al. (1994) $(0.01 \mathrm{~cm})$. Larger changes in the thickness of the diffusive sublayer (0.01 to $0.1 \mathrm{~cm}$ ), as might occur in regions such as Southampton Water, reduced the modeled oxygen flux and the carbon oxidation rates by up to $22 \%$ (Figs. 3a \& 4a). These latter findings suggest the need for experimental work investigating the effect on oxygen fluxes of larger changes in the DBL thickness than those previously reported. Such experiments would provide a firmer basis for the conclusions of Jørgensen \& Boudreau (2001) and the work presented here.

In a comparative study of measurements of sedimentary oxygen consumption under laboratory and in situ environments in which OPDs were in the range 0.08 to $0.45 \mathrm{~cm}$, Glud et al. (2003) found that laboratory rates underestimated in situ rates (by up to $\sim 50 \%$, estimated from their Fig. 11b). Although the cause of this discrepancy could not be explained, these authors argued that the similarity in the mean DBL thickness between the 2 environments (laboratory and in situ) excluded the
DBL as the cause of the laboratory underestimation. Glud et al. (2003) acknowledged previous work showing that the technique they adopted of estimating the DBL thickness with a microsensor inserted from above the sediment, introduces variable uncertainty in the estimate (25 to $45 \%$, Glud et al. 1994). It is not unreasonable to suppose that the introduction of such variability, although applicable to both the laboratory and in situ environments, may in part contribute to the measured difference in oxygen consumption rates in their study, especially given that the maximum in situ DBL $(0.0706 \mathrm{~cm})$ was higher than the maximum laboratory value $(0.059 \mathrm{~cm})$. The model presented here predicts that the larger the DBL thickness the lower the rates of sedimentary oxygen consumption. However, according to the model, even the highest possible difference between in situ and laboratory maximum DBLs $(\sim 0.05 \mathrm{~cm})$ could not account for the $\sim 50 \%$ differences in the measurements between the laboratory and in situ conditions.

\section{Steady state model predictions vs. dynamic changes in the DBL thickness}

For the steady state model results presented here to be applicable to dynamic regions such as Southampton Water, the effects of the DBL on the benthic fluxes would need to occur instantaneously. Reimers et al. (2001) used a time-dependent model to determine the time taken for sedimentary oxygen uptake to reach a new steady state in response to a change in the DBL (halving and doubling of thickness $0.05 \mathrm{~cm}$ ) over deep sea sediments. These authors found the time taken to be in the region of 10 to $20 \mathrm{~h}$. Such time scales are longer than the frequency of the changes in the DBL thickness (minutes to hours) that would occur in the hydrodynamically active environment of Southampton Water (Fig. 5). This means that the steady state benthic fluxes presented here could not be established in time in response to a particular change in the DBL. Consequently, these model results may not reflect the actual changes in benthic fluxes that might occur. To gauge the significance of this, a more detailed look at the model results of Reimers et al. (2001) is needed. These authors showed that the changes in the DBL caused a less than $5 \%$ change in the oxygen flux once steady state was re-established (i.e. after 10 to $20 \mathrm{~h}$ ). This small influence of the DBL on oxygen fluxes, compared to the model results presented here, results from the fact that oxygen penetration was set at $2 \mathrm{~cm}$. That is, only a small fraction of the total porewater profile of oxygen was contained in the DBL. However, the model results in Reimers et al. (2001) also show that instantaneous changes in the oxygen fluxes of $\sim 10$ to $20 \%$ occurred 
(estimated from their Fig. 10.3) in response to the sudden changes in the thickness of the DBL. This instantaneous response is likely to be even more pronounced in sediments with lower OPDs which also meet the other criteria for DBL influenced sediments (i.e. low near-bed current velocities, oxygen fluxes across the SWI are diffusive, oxygen consumption is dominated via organic carbon degradation and the sediments are finegrained). Glud et al. (1994) calculated that a new steady state oxygen profile took $6 \mathrm{~min}$ to establish following a change in the DBL thickness above highly reactive sediments. This calculation is supported by a more recent theoretical study (Higashino et al. 2004) suggesting that steady state conditions can be reached in similar time as sedimentary oxygen consumption rates increase. This is the same as having a higher value of $k$. Hence, the steady state results from the model presented here may reflect the instantaneous response of benthic fluxes to dynamic changes in the DBL suggested in Reimers et al. (2001). This reinforces the importance of considering the DBL without prior knowledge of the sediment conditions (physical and biogeochemical). To quantify the time-integrated (e.g. annual) effect of changes in the DBL caused by temporal variations in near-bed current velocities on benthic fluxes, a dynamic model is needed. Such models already exist (e.g. Soetaert et al. 1996) and readily lend themselves to future investigations into the temporal variations in DBL thicknesses on benthic processes.

\section{Global significance}

The results of this modelling study apply to sediments in which (1) carbon oxidation rates are fuelled mainly by oxygen, (2) OPDs are low $(<0.5 \mathrm{~cm})$ and (3) fluxes across the SWI are diffusive. Most field studies show that when Conditions 1 and 2 are met (often in shallow sediments), the exchange rates of solutes across the SWI are too high to be accounted for by diffusion alone (e.g. Rysgaard et al. 2001), although not always (Glud et al. 2003). Other studies find that when Conditions 1 and 3 are met (often in deep sea sediments), OPDs are high ( $\geq 1 \mathrm{~cm}$, e.g. Jahnke 1989, Lohse et al. 1998) relative to the thickness of the DBL. Few studies show that all 3 conditions occur at a particular site (Stn 2 in Silverberg et al. 2001 [Loch Etive], Overnell 2002). However, it is not unlikely that a transitional sedimentary zone exists between shallow coastal shelf sea areas and the continental slope in which (1) OPDs change from a few millimetres to a few centimetres, (2) solute exchange goes from being dominated by irrigation, turbulent diffusion and advection to being diffusion controlled and (3) oxygen consumption goes from being driven by reoxidation processes to being fuelled by organic carbon mineralisation. In such a transition zone, it is proposed that sedimentary conditions exist in which the DBL may influence both solute fluxes and diagenetic reactions in the manner demonstrated in this modelling study. Even if such a transition zone is doubted, the fact that changes in the DBL thickness have been shown to alter measured oxygen fluxes across the SWI (Jørgensen \& Des Marais 1990, Huettel et al. 2003, Lorke et al. 2003) provides support for the main conclusion that studies of sedimentary oxygen and nutrient (especially ammonium and nitrate, Fig. 3b,c) fluxes should not exclude the potential effects of the DBL.

\section{CONCLUSIONS}

This work suggests that it is unwise to neglect the presence of the diffusive sublayer in measurements of benthic fluxes for fine-grained sediments with low OPDs in which oxygen is primarily consumed by the decomposition of organic matter and where the dissolved flux across the SWI is diffusive. The modelling results presented here suggest that the impact of changes in the DBL increases with increasing organic carbon reactivity. Fluxes of oxygen and ammonium across the SWI decreased by up to 22 and $30 \%$, respectively, in response to thicker DBLs in the range 0.01 to $0.1 \mathrm{~cm}$. The reduction in oxygen fluxes was greater the higher the organic carbon reactivity ( $k=1$ to $40 \mathrm{yr}^{-1}$ ). Sulphate fluxes also decreased by between 30 and $>99 \%$ although these were of the order $10^{-5} \mathrm{~mol} \mathrm{~m}^{-2}$ $\mathrm{yr}^{-1}$. Fluxes of nitrate increased by a maximum of $380 \%$ for high organic carbon reactivities $\left(k=40 \mathrm{yr}^{-1}\right)$ and effluxes decreased by up to $80 \%$ for lower reactivities with increasing DBL thickness. The decrease in oxygen fluxes was caused by the lowering of the OPD with thicker DBLs which meant that a greater proportion of the oxygen concentration gradient was contained within the DBL. The reduction in oxygen fluxes had the effect of reducing rates of organic carbon degradation by up to $22 \%$. This implicates the DBL as a potential factor in organic carbon preservation when organic reactivity is high. The reduced degradation lowered the production of ammonium which caused the reduction in the ammonium effluxes. This reduced ammonium supply to the overlying water suggests that the DBL may also be a factor in controlling phytoplankton production in areas where primary production is reliant on nutrients regenerated from the sediments. The increase in demand for nitrate with increasing sublayer thickness was fuelled by the increase in rates of denitrification (by up to $8 \%$ ). This enhancement was caused by the reduction in oxygen penetration rather than by direct effects of the DBL. The large percentage changes in the sulphate flux 
occurred because the changes in the magnitude of both sulphide oxidation and sulphate reduction, which drive the demand for sulphate, were large in comparison to the sulphate flux. Rates of nitrification decreased by between 12 and $18 \%$, fuelled by reductions in sedimentary oxygen concentrations with increasing DBL.

Benthic fluxes are often derived from core incubations using a high stirring rate (e.g. 300 rpm). The latter assumes that the DBL is absent. Such an approach is based on assumptions about high current velocities near the sediment surface. Actual measurements of near-bed current speeds suggest that DBLs in the observed range of thicknesses (e.g. 0.016 to $0.12 \mathrm{~cm}$ ) may be established in a macro-tidal estuary. The presence of these DBL thicknesses in such a dynamic environment makes it reasonable to assume that the establishment of the DBL may be widespread, particularly as shallow coastal/estuarine sediments underlying productive waters are likely to receive large inputs of highly reactive organic carbon. It is therefore recommended that the use of high stirring rates is inappropriate for sediments in which the following 5 criteria are met: (1) near-bottom current speeds are low $\left(<\sim 8 \mathrm{~cm} \mathrm{~s}^{-1}\right) ; \quad(2)$ the sediments are fine-grained (muddy) with low permeability $\left(<10^{-12} \mathrm{~m}^{-2}\right.$, Huettel et al. 2003); (3) sedimentary oxygen consumption is dominated by organic carbon degradation; (4) OPDs are low $(<0.5 \mathrm{~cm})$; and (5) solute fluxes are diffusive. Consequently, the presence of a diffusive sublayer should always be considered when prior knowledge of these 5 criteria is uncertain.

Acknowledgements. This work was part of the JoNuSSONUS (Joint Nutrient Study-Southern Nutrient Study) programme funded by the Ministry of Agriculture, Fisheries and Food and the Department of the Environment, Transport and the Regions (all UK). The views expressed are those of the authors and do not reflect the policies of the funding departments. We thank 3 anonymous referees for helping to improve the quality of this paper and R. Turnewitsch for commenting on an early draft.

\section{LITERATURE CITED}

Andersen FO (1996) Fate of organic carbon added as diatom cells to oxic and anoxic marine sediment microcosms. Mar Ecol Prog Ser 134:225-233

Archer D, Emerson S, Smith CR (1989) Direct measurement of the diffusive sublayer at the deep sea floor using oxygen microelectrodes. Nature 340:623-626

Berner RA (1980) Early diagenesis - a theoretical approach. Princeton University Press, Princeton, NJ

Boudreau BP (1997) Diagenetic models and their implementation. Springer-Verlag, Berlin

Canfield DE, Jørgensen BB, Fossing H, Glud R and 6 others (1993) Pathways of organic-carbon oxidation in 3 Continental-maargin sediments. Mar Geol 113:27-40
Collins KJ, Mallinson JJ (2000) Marine habitats and communities. In: Collins M, Ansell K (eds) Solent Science-a review. Elsevier Science, Amsterdam, p 247-259

Cowan J, Pennock R, Boynton W (1996) Seasonal and interannual patterns of sediment-water nutrient and oxygen fluxes in Mobile Bay Alabama (USA): regulating factors and ecological significance. Mar Ecol Prog Ser 141: $229-245$

Dade WB, Hogg AJ, Boudreau BP (2001) Physics of flow above the sediment-water interface. In: Boudreau BP, Jørgensen BB (eds) The benthic boundary layer. Transport processes and biogeochemistry. Oxford University Press, New York, p 4-43

de Haas H, van Weering TCE, de Stieger H (2002) Organic carbon in shelf seas:sinks or sources processes and products. Cont Shelf Res 22:691-717

Fisher T, Carlson P, Barber R (1982) Sediment nutrient regeneration in three North Carolina estuaries. Estuar Coast Shelf Sci 14:101-116

Forster S, Huettel M, Ziebis W (1996) Impact of boundary layer flow velocity on oxygen utilisation in coastal sediments. Mar Ecol Prog Ser 143:173-185

Glud RN, Gundersen JK, Revsbech NP, Jørgensen BB (1994) Effects on the benthic diffusive boundary-layer imposed by microelectrodes. Limnol Oceanogr 39:462-467

Glud RN, Gundersen JK, Revsbech NP, Jørgensen BB, Huttel $M$ (1995) Calibration and performance of the stirred flux chamber from the benthic lander Elinor. Deep-Sea Res I 42:1029-1042

Glud RN, Forster S, Huettel M (1996) Influence of radial pressure gradients on solute exchange in stirred benthic chambers. Mar Ecol Prog Ser 141:303-311

Glud RN, Gundersen JK, Roy H, Jørgensen BB (2003) Seasonal dynamics of benthic $\mathrm{O}_{2}$ uptake in a semienclosed bay: importance of diffusion and faunal activity. Limnol Oceanogr 48:1265-1276

Hall POJ, Anderson LG, Rutgers van der Loeff MM, Sundby B, Westerlund SFG (1989) Oxygen-uptake kinetics in the benthic boundary-layer. Limnol Oceanogr 34:734-746

Hedges JI, Keil RG (1995) Sedimentary organic-matter preservation - an assessment and speculative synthesis. Mar Chem 49:81-115

Higashino M, Gantzer CJ, Stefan HG (2004) Unsteady diffusional mass transfer at the sediment/water interface: theory and significance for SOD measurement. Wat Res 38: $1-12$

Huettel M, Roy H, Precht E, Ehrenhauss S (2003) Hydrodynamical impact on biogeochemical processes in aquatic sediments. Hydrobiologia 494:231-236

Jahnke RA, Emerson SR, Reimers CE, Schuffert J, Ruttenberg K, Archer D (1989) Benthic recycling of biogenic debris in the eastern tropical Atlantic Ocean. Geochim Cosmochim Acta 53:2947-2960

Jørgensen BB (1982) Mineralisation of organic matter in the sea bed. Nature 296:643-645

Jørgensen BB, Boudreau BP (2001) Diagenesis and sediment-water exchange. In: Boudreau BP, Jørgensen BB (eds) The benthic boundary layer. Transport processes and biogeochemistry. Oxford University Press, New York, p 211-244

Jørgensen BB, Marais DJD (1990) The diffusive boundarylayer of sediments - oxygen microgradients over a microbial mat. Limnol Oceanogr 35:1343-1355

Kelly-Gerreyn BA, Hydes DJ, Trimmer M, Nedwell DB (1999) Calibration of an early diagenesis model for high nitrate low reactive sediments in a temperate latitude estuary (Great Ouse, UK). Mar Ecol Prog Ser 177:37-50 
Kelly-Gerreyn BA, Trimmer M, Hydes DJ (2001) A model discriminating denitrification and dissimilatory nitrate reduction to ammonium in a temperate estuarine sediment. Mar Ecol Prog Ser 220:33-46

Le Roux JP (2004) An integrated law of the wall for hydrodynamically transitional flow over plane bed. Sed Geol 163: 311-321

Lohse L, Epping E, Helder W, van Raaphorst W (1996) Oxygen porewater profiles in continental shelf sediments of the North Sea:turbulent versus molecular diffusion. Mar Ecol Prog Ser 145:63-75

Lohse L, Helder W, Epping EHG, Balzer W (1998) Recycling of organic matter along a shelf-slope transect across the NW European Continental Margin (Goban Spur). Prog Oceanogr 42:77-110

Lorke A, Muller B, Maerki M, Wuest A (2003) Breathing sediments: the control of diffusive transport across the sediment-water interface by periodic boundary-layer turbulence. Limnol Oceanogr 48:2077-2085

Mackin JE, Swider KT (1989) Organic matter decomposition pathways and oxygen consumption in coastal marine sediments. J Mar Res 47:681-716

Nedwell DB, Trimmer M (1996) Nitrogen fluxes through the upper estuary of the Great Ouse, England: the role of the bottom sediments. Mar Ecol Prog Ser 142:273-286

Overnell J (2002) Manganese and iron profiles during early diagenesis in Loch Etive Scotland. Application of two diagenetic models. Estuar Coast Shelf Sci 54(1):33-44

Rabouille C, Gaillard JF (1991) A coupled model representing the deep sea organic carbon mineralisation and oxygen consumption in surficial sediments. J Geophys Res 96:2761-2776

Reimers C, Jahnke RA, Thomsen L (2001) In situ sampling in the benthic boundary layer. In: Boudreau BP, Jørgensen BB (eds) The benthic boundary layer. Transport processes and biogeochemistry. Oxford University Press, New York, p 245-268

Revsbech N, Jørgensen B, Blackburn T (1980) Oxygen in the sea bottom measured with a microelectrode. Science 207:1355-1356

Editorial responsibility: Otto Kinne (Editor-in-Chief), Oldendorf/Luhe, Germany
Rysgaard S, Fossing H, Jensen MM (2001) Organic matter degradation through oxygen respiration dentrification and manganese iron and sulfate reduction in marine sediments (the Kattegat and the Skagerrak). Ophelia 55:77-91

Santschi PH, Bower P, Nyffeler UP, Azevedo A, Broecker WS (1983) Estimates of the resistance to chemical-transport posed by the deep-sea boundary-layer. Limnol Oceanogr 28:899-912

Santschi PH, Anderson RF, Fleisher MQ, Bowles W (1991) Measurements of diffusive sublayer thicknesses in the ocean by alabaster dissolution and their implications for the measurements of benthic fluxes. J Geophys Res Oceans 96:10641-10657

Silverberg N, Sundby B, Mucci A, Zhong SJ, Arakaki T, Hall P, Landen A, Tengberg A (2000) Remineralization of organic carbon in eastern Canadian continental margin sediments. Deep-Sea Res II 47:699-731

Slomp CP, Malshaert JFP, Lohse L, VanRaaphorst W (1997) Iron and manganese cycling in different sedimentary environments on the North Sea continental margin. Cont Shelf Res 17:1083-1117

Soetaert K, Herman PMJ, Middelburg JJ (1996) A model of early diagenetic processes from the shelf to abyssal depths. Geochim Cosmochim Acta 60:1019-1040

Tengberg A, Stahl H, Gust G, Muller V, Arning U, Andersson $\mathrm{H}$, Hall POJ (2004) Intercalibration of benthic flux chambers I. Accuracy of flux measurements and influence of chamber hydrodynamics. Prog Oceanogr 60: $1-28$

Upton AC, Nedwell DB, Parkes RJ, Harvey SM (1993) Seasonal benthic microbial activity in the southern North Sea-oxygen-uptake and sulfate reduction. Mar Ecol Prog Ser 101:273-281

Velegrakis A (2000) Geology geomorphology and sediments of the Solent system. In:Collins M, Ansell K (eds) Solent science - a review. Elsevier Science, Amsterdam, p 21-43

Williams JJ, Humphery JD, Hardcastle P, Wilson DJ (1998) Field observations of hydrodynamic conditions and suspended particulate matter in the southern North Sea. Cont Shelf Res 18:1215-1233

Submitted: March 18, 2003; Accepted: January 31, 2005

Proofs received from author(s): April 26, 2005 